\title{
Upper cervical spine dysfunction and dizziness
}

\author{
Yun-Hee Sung* \\ Department of Physical Therapy, College of Health Sciences, Kyungnam University, Changwon, Korea
}

Although various causes of dizziness have been identified, many patients suffer from dizziness of unknown etiology and continue to visit hospitals to resolve their symptoms. Problems that occur in the ligaments or muscles of the upper cervical spine can cause confusion in proprioception. These changes can convey misinformation to the vestibular nucleus, resulting in abnormal reactions that can lead to cervicogenic dizziness (CGD). Though CGD remains controversial, it should be considered while diagnosing patients with dizziness. Understanding CGD can help create treatment strategies for them. This article suggested a relationship between the structure and function of the upper cervical spine and dizziness, and presented evaluations and treatments for the same.

Keywords: Dizziness, Cervical vertebrae, Cervicogenic dizziness

\section{INTRODUCTION}

Dizziness is common complaints affecting about $20 \%-30 \%$ of the general population (Li and Peng, 2015; Strupp and Brandt, 2008). Although the cause, diagnosis, and treatment of dizziness have been revealed, many patients still complain of dizziness despite having no problems in the vestibular and cardiovascular systems or brain damage (Li and Peng, 2015; Takahashi, 2018). The patients visit several hospitals to treat their symptoms, but do not obtain satisfactory results often (Takahashi, 2018). They paid out $\$ 1,000-2,000$ to diagnose the cause of dizziness with expensive neuroimaging (Grill et al., 2014; Li et al., 2000).

Cervicogenic dizziness (CGD) is caused by functional problem of the cervical spine associated with postural alignment, proprioception, range of motion, or vertebrobasilar artery blood flow (Reid et al., 2014a; Reid et al., 2017; Wrisley et al., 2000). Patients with CGD complain of unsteadiness, neck pain, stiffness, headache, dysphagia, nausea, visual disturbances, ear fullness, tinnitus, temporomandibular joint pain, and psychological problems (Malmström et al., 2007; Reid et al., 2012). Recently, Chu et al. (2019) suggested that if vestibular and cardiovascular pathologies have been ruled out, CGD should be suspected. Takahashi (2018) reported that $90 \%$ of the 1,000 patients in his study with general dizziness had
CGD. Although many researchers have investigated the interrelation between cervical spine dysfunctions and dizziness, it remains controversial. Currently, CGD has been excluded from the diagnosis. Therefore, this study was to investigate the association between the upper part of the cervical spine and dizziness.

\section{STRUCTURE AND FUNCTION}

\section{Ligaments}

The transverse, alar, and capsular ligaments are important in stabilizing the upper cervical spines. The transverse ligament originates from a small tubercle on the medial surface of the lateral mass of the atlas, and inserts into the contralateral tubercle. Thus, it restricts anterior displacement of the atlas and flexion of the head (Steilen et al., 2014). The right and left alar ligaments run from the respective sides of the foramen magnum of the skull to the dens of the axis. They may be oblique or vertical, and limit the axial rotation and contralateral lateral flexion of the head (Steilen et al., 2014). The capsular ligaments surround the facet joints. They provide neck stability, especially during axial rotation (Rasoulinejad et al., 2012; Steilen et al., 2014). They also protect the nervous system such as brain stem, and spinal cord during excessive movements (Cusick and Yoganandan, 2002; Steilen et al., 2014).
*Corresponding author: Yun-Hee Sung (iD https://orcid.org/0000-0002-4877-9784 Department of Physical Therapy, College of Health Sciences, Kyungnam University, 7 Kyungnamdaehak-ro, Masanhappo-gu, Changwon 51767, Korea

E-mail: sungpt97@kyungnam.ac.kr

Received: August 6, 2020 / Accepted: September 4, 2020
This is an Open Access article distributed under the terms of the Creative Commons Attribution Non-Commercial License (https://creativecommons.org/licenses/by-nc/4.0/) which permits unrestricted non-commercial use, distribution, and reproduction in any medium, provided the original work is properly cited. 


\section{Muscles}

The suboccipital muscles locate in the deepest layer of the neck. These are four paired muscles (rectus capitis posterior major, rectus capitis posterior minor, obliquus capitis superior, and obliquus capitis inferior). Unilateral contraction of these muscles induces head rotation, and bilateral contraction causes head extension (Yamauchi et al., 2017). These muscles have a high muscle spindle density that not only allows flexible movement, but also act as specific sensory receptors (Kulkarni et al., 2001). Therefore, these muscles allow to control delicate movements in atlanto-occipital (C1-C0) and atlanto-axial (C1-C2) joint (Yamauchi et al., 2017). However, sustained and excessive stress in the cervical spine resulted from incorrect posture causes problems in these muscles. (Yamauchi et al., 2017). McPartland et al. (1997) reported that weakness of cervical muscle after whiplash is associated with chronic neck pain and poor balance.

The deep cervical flexor muscles comprise of the longus colli and longus capitis muscles (Harrison et al., 2003). There are many proprioceptors in these muscles. These proprioceptors respond to the initial movement of a head or upper arm and contract these muscles. Thus, dysfunction of proprioceptors in these muscles could guide inappropriate movement in neck (Falla et al., 2004). As well, of these muscles, weak longus colli muscles can lead to cervical spine instability. The cervical spine instability would stimulate more the sympathetic trunk that is structurally close. This can be caused vertigo symptoms (Ibrahim et al., 2010; Liu et al., 2017; Saylam et al., 2009).

\section{Proprioception}

The proprioceptive system is extremely well developed in the cervical zygapophyseal joints. These joints are highly innervated by mechanoreceptive and nociceptive free nerve endings ( $\mathrm{Li}$ and Peng, 2015). Hulse (1983) found that $50 \%$ of all cervical proprioceptors were present in the joint capsules from $\mathrm{C} 1-\mathrm{C} 3$. In addition, the deep upper cervical muscles have abundant mechanoreceptors in the $\gamma$-muscle spindles, which are highly sensitive to head yaw rotation (Chan et al., 1987; Pettorossi and Schieppati, 2014; Sterling et al., 2003). These abundant receptors play an important role in controlling afferent cervical activity, and controlling the movement of the eyes and body posture (Li and Peng, 2015). De Vries et al. (2015) reported that cervical proprioception has a neurological basis in muscle spindles rather than in the Golgi tendon organ, cutaneous receptors, and joint receptors. Afferent information from the cervical muscle and head movement related the visual and vestibular system converges in the vestibular nuclei (Corneil et al.,
2002; de Vries et al., 2015). Accurate head-on-trunk orientation can be achieved by proprioceptive information of the cervical spine without vestibular information (de Vries et al., 2015; Malmström et al., 2009). However, changes in these structures due to direct trauma, muscular fatigue, degenerative changes, or direct pain can progress to subsequent damage of the ligament or muscle fibers, leading to instability at the cervical zygapophyseal joints (Chen et al., 2009; L'Heureux-Lebeau et al., 2014; Steilen et al., 2014). The function of receptors in the cervical spine can be altered. Damaged receptors in the upper cervical region relay abnormal signals to the vestibular nucleus, and a sensory mismatch between the vestibular and cervical inputs could result in cervicogenic vertigo (Bracher et al., 2000; Li and Peng, 2015; Michels et al., 2007).

\section{Kinematics}

The atlas articulates with the occipital condyles. Normal flexion to hyperextension at $\mathrm{C} 1-\mathrm{C} 0$ joint is between $15^{\circ}-20^{\circ}$ (Swartz et al., 2005). A C1-C2 joint has anatomically biconvex nature. Thus, flexion or extension movement in cervical spine often leads to motion in the opposite direction that is experienced in the atlas (Swartz et al., 2005). Rotation at C1-C0 joint is not possible due to the depth of the atlas sockets (Bogduk and Mercer, 2000). However, C1-C2 joint is possible. About $50 \%$ of all cervical spine rotation occurs at the C1-C2 (Steilen et al., 2014). As three primary ligaments (apical, alar, and transverse ligament) hold the dens of the $\mathrm{C} 2$, the normal range of rotation of $\mathrm{C} 1$ on $\mathrm{C} 2$ is $50^{\circ}$ on each side (Bogduk and Mercer, 2000; Swartz et al., 2005).

\section{ASSESSMENT}

\section{Dizziness handicap inventory}

The dizziness handicap inventory (DHI) is a questionnaire to evaluate dizziness (Jacobson and Newman, 1990). The DHI has been used to quantify the morbidity associated with dizziness in patients with vestibular system or other origin injuries (Ardiç et al., 2006; Tamber et al., 2009; Treleaven et al., 2005). The DHI is a self-reported questionnaire that includes 25 questions (seven physical, nine functional, and nine emotional questions). The physical subscale is well relevant to patients with CGD in Q1, Q11, and Q25 questions. The emotional subscale (Q9) showed a very low score in CGD patients than in those with general dizziness (Reid et al., 2017). The total score adds up the scale of answers, and the higher the score indicates severe dizziness and dysfunction (Treleaven, 2006; Whitney et al., 2004). It is reported that patients' symptoms are relieved when the total DHI score is reduced by at 
least 18 points (Jacobson and Newman, 1990). Test-retest reliability ( $r=0.92$ to 0.97 ) and internal consistency ( $\alpha=0.72$ to 0.89 ) have been shown to be high (Treleaven, 2006).

\section{Craniocervical flexion test}

This test is widely used to confirm selectively contracting the deep neck flexors (longus capitis and longus colli) during active craniocervical flexion in supine position (Araujo et al., 2018; Juul et al., 2013). A clinician places a pressure biofeedback unit under the patient's head and trains the patient to perform appropriate craniocervical flexion movements. The clinician should observe that the patient contracts only the deep neck flexor muscles without contracting the superficial neck flexors (e.g., sternocleidomastoid and anterior scalene) during the movements. Patients start at $22 \mathrm{mmHg}$ and increase the steps by $2 \mathrm{mmHg}$ to $30 \mathrm{mmHg}$ (Araujo et al., 2018; Juul et al., 2013). This test can also be used to strengthen the deep neck flexors (Jull and Falla, 2016; Jull et al., 2008; Juul et al., 2013).

\section{Alar-ligament stress test}

The alar ligaments originated from the ipsilateral of foramen magnum to the posterior dens of the axis. They are to limit axial rotation. They have the strongest tension during rotation and flexion (Steilen et al., 2014). To test the alar ligament, the patient is made to flex the head slightly in a seated or supine position. The clinician stabilizes the patient's spinous process of $\mathrm{C} 2$ using a pincer grasp, and passively performs lateral flexion, rotation, or lateral shear, separately (Harry et al., 2019). A positive sign is a lack of movement of the $\mathrm{C} 2$ spinous process during movement (Harry et al., 2019; Reiley et al., 2017). The rotation stress has a sensitivity of $80 \%$ and specificity of $69.2 \%$. Both the side-bending stress and lateral shear have a sensitivity of $80 \%$ and specificity of $76.9 \%$ (Harry et al., 2019).

\section{Sharp-Purser test}

The Sharp-Purser test is to assess the integrity of the transverse ligament. This helps to maintain the position of the odontoid process on atlas (Reiley et al., 2017). Many clinicians use the test to identify C1-C2 instability prior to the manipulation, joint mobilization, or dry needling of the upper cervical spine (Mansfield et al., 2020). The patient is seated with slightly flexed head position. The clinician fixes the spinous process of axis using a pincer grasp, and the opposite hand applies an anterior to posterior translation force on the patient's forehead. If symptoms recur during forward flexion or disappear during posterior translation, $\mathrm{C} 1-\mathrm{C} 2$ instabili- ty should be suspected. In addition, it is a positive sign if it is displaced by more than $4 \mathrm{~mm}$ during posterior translation (Reiley et al., 2017).

\section{Cervical joint position error test}

The cervical joint position error test is used to assess the function of cervical proprioception in patients with neck pain, dizziness, and balance problems (Lee et al., 2008; Treleaven et al., 2006). It reflects afferent input from the receptors of joint and muscle in neck (Treleaven et al., 2003). The patient wears a laser cap and eye patch, sits $90 \mathrm{~cm}$ away from the wall, and actively moves the head and neck in the specified direction (flexion, extension, or rotation). Movement is measured in 10 trials in each direction, and then the patient returns to the natural head posture. The difference between the start (zero) and return positions is calculated in degrees for each trial. If the difference is more than $4.5^{\circ}$, it indicates dysfunction of neck proprioception (Pinsault et al., 2008; Quartey et al., 2019; Treleaven et al., 2003).

\section{Vertebrobasilar insufficiency test}

The vertebrobasilar insufficiency (VBI) test is to check blood flow in the vertebral artery (Kerry and Taylor, 2006). The clinician performs a combined extension and rotation of the cervical spine or rotation alone (Vidal, 2004; Zaina et al., 2003). Patients with VBI complain of dizziness, drop attacks, diplopia, dysarthria, dysphagia, ataxia, nausea, numbness, and nystagmus during the test (Thiel and Rix, 2005). As VBI can generate cerebral ischemia, leading to severe morbidity, patient with positive sign has to transfer to neurology (Asavasopon et al., 2005). Among the causes of VBI, poor head and neck posture and malalignment of the upper cervical spine can cause mechanical compromise, resulting in decreased velocity of vertebrobasilar blood flow and dizziness (Biesinger, 1988; Fitz-Ritson, 1991).

\section{TREATMENT}

\section{Sensory-motor control exercise}

Impact of neck pain on motor output of cervical muscles: Impaired motor output of cervical muscles represents decreased strength, endurance, and force steadiness, as well as alteration in cervical muscle behavior, such as decreased activity of deep postural muscles, reduction of directional specificity, delayed onset of muscle responses, muscle fatigue, and increased neck muscle cocontraction (Blomgren et al., 2018; Falla et al., 2004; Schomacher et al., 2012). Thoomes-de Graaf and Schmitt (2012) showed that 
training of deep cervical flexors could increase the range of motion of the cervical spine, and reduce dizziness, pain, and limitations in activities in a patient with chronic nonspecific neck pain after prolonged bed rest.

Some patients with neck pain complain of impaired proprioception and postural control (O'Leary et al., 2009). To solve these problems, many therapists apply various exercises such as headneck recognition exercises, oculomotor exercises, or balance training (Gallego Izquierdo et al., 2016; Kristjansson and Treleaven, 2009). These approaches enhance sensorimotor control, and reduce neck pain and disability (Ekvall Hansson et al., 2006; Jull et al., 2007). Gallego Izquierdo et al. (2016) showed that cervical proprioception training has an effect on not only improvement of pain and disability, but also the coordination between the deep and superficial cervical flexors in patients with chronic neck pain.

\section{Mobilization}

As $50 \%$ of all cervical proprioceptors is in the joint capsules of C1-C3, abnormal mechanical stress of the cervical zygapophyseal joints is related with poor balance and dizziness (Hulse, 1983; Wrisley et al., 2000). Colledge et al. (1996) reported that cervical spondylosis was the cause of dizziness in $65 \%$ of the elderly. Thus, upper cervical degeneration or neck injury is one of causes of CGD. The CGD occurs a mismatch of sensory information (Reid et al., 2014a; Treleaven, 2006; Wrisley et al., 2000; Young and Chen, 2003). To solve the CGD, many therapists apply manual therapy to increase stimulation of proprioceptors to the upper cervical spine (Reid et al., 2008).

Mulligan introduced an intervention for CGD called sustained natural apophyseal glides (SNAGs) (Reid et al., 2014a). The SNAGs are safe and effective. It had an immediate and sustained effect in reducing dizziness, neck pain, and disability (Reid et al., 2008, Reid et al., 2012). Hall et al. (2007) provided evidence for the efficacy of SNAGs technique for C1-C2 in patients with cervicogenic headaches. Maitland mobilization is also a manual therapy technique for the management of cervical pain and CGD (Reid et al., 2012; Reid et al., 2014b). Both SNAGs and Maitland mobilization provide reductions in intensity and frequency of chronic CGD (Reid et al., 2014b).

\section{CONCLUSIONS}

In summary, dizziness is one of the symptoms caused by damage to the vestibular, cardiovascular, or nervous system. Clinicians find the cause from related tests. Among patients complaining of dizziness, various tests are performed for diagnosis, but the test results are often normal. It is necessary for the clinician to suspect cervical dizziness and conduct related tests. If the test result is abnormal, the clinician should diagnose cervical dizziness and proceed with related treatment. Although cervical dizziness is controversial, we will have to make efforts to understand and solve the dizziness from a variety of perspectives (Fig. 1).

\section{CONFLICT OF INTEREST}

No potential conflict of interest relevant to this article was reported.

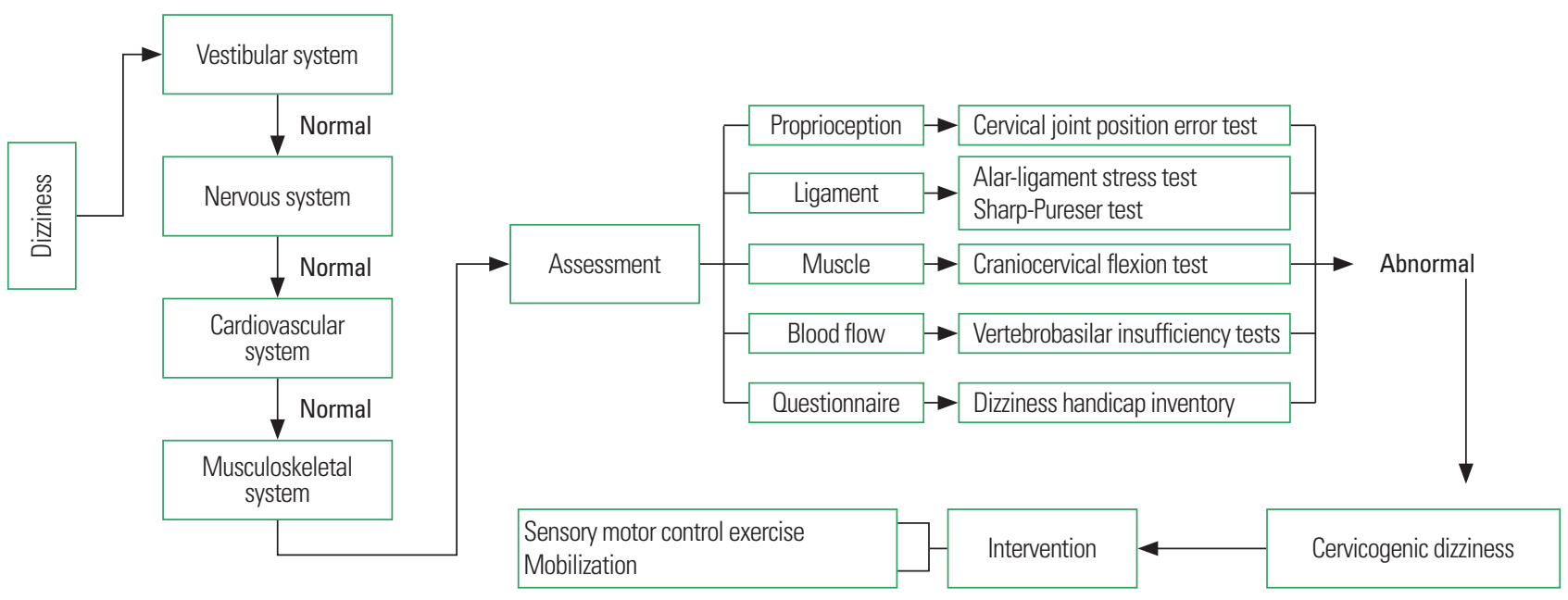

Fig. 1. Schematic flow for diagnosing cervicogenic dizziness. 


\section{REFERENCES}

Araujo FX, Ferreira GE, Scholl Schell M, Castro MP, Silva MF, Ribeiro DC. Measurement properties of the craniocervical flexion test: a systematic review protocol. BMJ Open 2018;8:e019486.

Ardiç FN, Topuz B, Kara CO. Impact of multiple etiology on dizziness handicap. Otol Neurotol 2006;27:676-680.

Asavasopon S, Jankoski J, Godges JJ. Clinical diagnosis of vertebrobasilar insufficiency: resident's case problem. J Orthop Sports Phys Ther 2005; 35:645-650.

Biesinger E. Vertigo caused by disorders of the cervical vertebral column. Diagnosis and treatment. Adv Otorhinolaryngol 1988;39:44-51.

Blomgren J, Strandell E, Jull G, Vikman I, Röijezon U. Effects of deep cervical flexor training on impaired physiological functions associated with chronic neck pain: a systematic review. BMC Musculoskelet Disord 2018;19:415.

Bogduk N, Mercer S. Biomechanics of the cervical spine, I: normal kinematics. Clin Biomech (Bristol, Avon) 2000;15:633-648.

Bracher ES, Almeida CL, Almeida RR, Duprat AC, Bracher CB. A combined approach for the treatment of cervical vertigo. J Manipulative Physiol Ther 2000;23:96-100.

Chan YS, Kasper J, Wilson VJ. Dynamics and directional sensitivity of neck muscle spindle responses to head rotation. J Neurophysiol 1987; 57:1716-1729.

Chen HB, Yang KH, Wang ZG. Biomechanics of whiplash injury. Chin J Traumatol 2009;12:305-314.

Chu ECP, Chin WL, Bhaumik A. Cervicogenic dizziness. Oxf Med Case Reports 2019;2019:476-478.

Colledge NR, Barr-Hamilton RM, Lewis SJ, Sellar RJ, Wilson JA. Evaluation of investigations to diagnose the cause of dizziness in elderly people: a community based controlled study. BMJ 1996;313:788-793.

Corneil BD, Olivier E, Munoz DP. Neck muscle responses to stimulation of monkey superior colliculus. II. Gaze shift initiation and volitional head movements. J Neurophysiol 2002;88:2000-2018.

Cusick JF, Yoganandan N. Biomechanics of the cervical spine part 4: major injuries. Clin Biomech (Bristol, Avon) 2002;17:1-20.

de Vries J, Ischebeck BK, Voogt LP, van der Geest JN, Janssen M, Frens MA, Kleinrensink GJ. Joint position sense error in people with neck pain: a systematic review. Man Ther 2015;20:736-744.

Ekvall Hansson E, Månsson NO, Ringsberg KA, Håkansson A. Dizziness among patients with whiplash-associated disorder: a randomized controlled trial. J Rehabil Med 2006;38:387-390.

Falla D, Jull G, Hodges PW. Feedforward activity of the cervical flexor muscles during voluntary arm movements is delayed in chronic neck pain. Exp Brain Res 2004;157:43-48.
Fitz-Ritson D. Assessment of cervicogenic vertigo. J Manip Physiol Ther 1991;14:193-198.

Gallego Izquierdo T, Pecos-Martin D, Lluch Girbés E, Plaza-Manzano G, Rodríguez Caldentey R, Mayor Melús R, Blanco Mariscal D, Falla D. Comparison of cranio-cervical flexion training versus cervical proprioception training in patients with chronic neck pain: a randomized controlled clinical trial. J Rehabil Med 2016;48:48-55.

Grill E, Strupp M, Müller M, Jahn K. Health services utilization of patients with vertigo in primary care: a retrospective cohort study. J Neurol 2014;261:1492-1498.

Hall T, Chan HT, Christensen L, Odenthal B, Wells C, Robinson K. Efficacy of a C1-C2 self-sustained natural apophyseal glide (SNAG) in the management of cervicogenic headache. J Orthop Sports Phys Ther 2007;37:100-107.

Harrison DE, Harrison DD, Betz JJ, Janik TJ, Holland B, Colloca CJ, Haas JW. Increasing the cervical lordosis with chiropractic biophysics seated combined extension-compression and transverse load cervical traction with cervical manipulation: nonrandomized clinical control trial. J Manipulative Physiol Ther 2003;26:139-151.

Harry Von P, Maloul R, Hoffmann M, Hall T, Ruch MM, Ballenberger N. Diagnostic accuracy and validity of three manual examination tests to identify alar ligament lesions: results of a blinded case-control study. J Man Manip Ther 2019;27:83-91.

Hulse M. Disequelibrium caused by a functional disturbance of the upper cervical spine, clinical aspects and differential diagnosis. Manual Med 1983;1:18-23.

Ibrahim M, Parmar H, Yang L. Horner syndrome associated with contusion of the longus colli muscle simulating a tumor. J Neuroophthalmol 2010;30:70-72.

Jacobson GP, Newman CW. The development of the dizziness handicap inventory. Arch Otolanryngol Head Neck Surg 1990;116:424-427.

Jull G, Falla D. Does increased superficial neck flexor activity in the craniocervical flexion test reflect reduced deep flexor activity in people with neck pain? Man Ther 2016;25:43-47.

Jull G, Falla D, Treleaven J, Hodges P, Vicenzino B. Retraining cervical joint position sense: the effect of two exercise regimes. J Orthop Res 2007;25:404-412.

Jull GA, O'Leary SP, Falla DL. Clinical assessment of the deep cervical flexor muscles: the craniocervical flexion test. J Manipulative Physiol Ther 2008;31:525-533.

Juul T, Langberg H, Enoch F, Søgaard K. The intra- and inter-rater reliability of five clinical muscle performance tests in patients with and without neck pain. BMC Musculoskelet Disord 2013;14:339.

Kerry R, Taylor AJ. Cervical arterial dysfunction assessment and manual therapy. Man Ther 2006;11:243-253. 
Kristjansson E, Treleaven J. Sensorimotor function and dizziness in neck pain: implications for assessment and management. J Orthop Sports Phys Ther 2009;39:364-377.

Kulkarni V, Chandy MJ, Babu KS. Quantitative study of muscle spindles in suboccipital muscles of human foetuses. Neurol India 2001;49:355359 .

L'Heureux-Lebeau B, Godbout A, Berbiche D, Saliba I. Evaluation of paraclinical tests in the diagnosis of cervicogenic dizziness. Otol Neurotol 2014;35:1858-1865.

Lee HY, Wang JD, Yao G, Wang SF. Association between cervicocephalic kinesthetic sensibility and frequency of subclinical neck pain. Man Ther 2008:13:419-425.

Li JC, Li CJ, Epley J, Weinberg L. Cost-effective management of benign positional vertigo using canalith repositioning. Otolaryngol Head Neck Surg 2000;122:334-339.

Li Y, Peng B. Pathogenesis, diagnosis, and treatment of cervical vertigo. Pain Physician 2015;18:E583-E595.

Liu XM, Pan FM, Yong ZY, Ba ZY, Wang SJ, Liu Z, Zhao WD, Wu DS. Does the longus colli have an effect on cervical vertigo?: A retrospective study of 116 patients. Medicine (Baltimore) 2017;96:e6365.

Malmström EM, Karlberg M, Fransson PA, Lindbladh J, Magnusson M. Cervical proprioception is sufficient for head orientation after bilateral vestibular loss. Eur J Appl Physiol 2009;107:73-81.

Malmström EM, Karlberg M, Melander A, Magnusson M, Moritz U. Cervicogenic dizziness - musculoskeletal findings before and after treatment and long-term outcome. Disabil Rehabil 2007;29:1193-1205.

Mansfield CJ, Domnisch C, Iglar L, Boucher L, Onate J, Briggs M. Systematic review of the diagnostic accuracy, reliability, and safety of the sharp-purser test. J Man Manip Ther 2020;28:72-81.

McPartland JM, Brodeur RR, Hallgren RC. Chronic neck pain, standing balance, and suboccipital muscle atrophy-a pilot study. J Manipulative Physiol Ther 1997;20:24-29.

Michels T, Lehmann N, Moebus S. Cervical vertigo-cervical pain: an alternative and efficient treatment. J Altern Complement Med 2007;13: 513-518.

O'Leary S, Falla D, Elliott JM, Jull G. Muscle dysfunction in cervical spine pain: implications for assessment and management. J Orthop Sports Phys Ther 2009;39:324-333.

Pettorossi VE, Schieppati M. Neck proprioception shapes body orientation and perception of motion. Front Hum Neurosci 2014;8:895.

Pinsault N, Fleury A, Virone G, Bouvier B, Vaillant J, Vuillerme N. Testretest reliability of cervicocephalic relocation test to neutral head position. Physiother Theory Pract 2008;24:380-391.

Quartey J, Ernst M, Bello A, Oppong-Yeboah B, Bonney E, Acquaah K, Asomaning F, Foli M, Asante S, Schaemann A, Bauer C. Comparative joint position error in patients with non-specific neck disorders and asymptomatic age-matched individuals. S Afr J Physiother 2019;75: 568.

Rasoulinejad P, McLachlin SD, Bailey SI, Gurr KR, Bailey CS, Dunning CE. The importance of the posterior osteoligamentous complex to subaxial cervical spine stability in relation to a unilateral facet injury. Spine J 2012;12:590-595.

Reid SA, Callister R, Katekar MG, Rivett DA. Effects of cervical spine manual therapy on range of motion, head repositioning, and balance in participants with cervicogenic dizziness: a randomized controlled trial. Arch Phys Med Rehabil 2014a;95:1603-1612.

Reid SA, Callister R, Katekar MG, Treleaven JM. Utility of a brief assessment tool developed from the dizziness handicap inventory to screen for cervicogenic dizziness: a case control study. Musculoskelet Sci Pract 2017;30:42-48.

Reid SA, Rivett DA, Katekar MG, Callister R. Comparison of mulligan sustained natural apophyseal glides and maitland mobilizations for treatment of cervicogenic dizziness: a randomized controlled trial. Phys Ther 2014b;94:466-476.

Reid SA, Rivett DA, Katekar MG, Callister R. Efficacy of manual therapy treatments for people with cervicogenic dizziness and pain: protocol of a randomised controlled trial. BMC Musculoskelet Disord 2012;13: 201.

Reid SA, Rivett DA, Katekar MG, Callister R. Sustained natural apophyseal glides (SNAGs) are an effective treatment for cervicogenic dizziness. Man Ther 2008;13:357-366.

Reiley AS, Vickory FM, Funderburg SE, Cesario RA, Clendaniel RA. How to diagnose cervicogenic dizziness. Arch Physiother 2017;7:12.

Saylam CY, Ozgiray E, Orhan M, Cagli S, Zileli M. Neuroanatomy of cervical sympathetic trunk: a cadaveric study. Clin Anat 2009;22:324-330.

Schomacher J, Farina D, Lindstroem R, Falla D. Chronic trauma-induced neck pain impairs the neural control of the deep semispinalis cervicis muscle. Clin Neurophysiol 2012;123:1403-1408.

Steilen D, Hauser R, Woldin B, Sawyer S. Chronic neck pain: making the connection between capsular ligament laxity and cervical instability. Open Orthop J 2014;8:326-345.

Sterling M, Jull G, Vicenzino B, Kenardy J, Darnell R. Development of motor system dysfunction following whiplash injury. Pain 2003;103: 65-73.

Strupp M, Brandt T. Diagnosis and treatment of vertigo and dizziness. Dtsch Arztebl Int 2008;105:173-180.

Swartz EE, Floyd RT, Cendoma M. Cervical spine functional anatomy and the biomechanics of injury due to compressive loading. J Athl Train 2005;40:155-161.

Takahashi S. Importance of cervicogenic general dizziness. J Rural Med 
2018;13:48-56.

Tamber AL, Wilhelmsen KT, Strand LI. Measurement properties of the dizziness handicap inventory by cross-sectional and longitudinal designs. Health Qual Life Outcomes 2009;7:101.

Thiel H, Rix G. Is it time to stop functional pre-manipulation testing of the cervical spine? Man Ther 2005;10:154-158.

Thoomes-de Graaf M, Schmitt MS. The effect of training the deep cervical flexors on neck pain, neck mobility, and dizziness in a patient with chronic nonspecific neck pain after prolonged bed rest: a case report. J Orthop Sports Phys Ther 2012;42:853-860.

Treleaven J. Dizziness handicap inventory (DHI). Aust J Physiother 2006; 52:67.

Treleaven J, Jull G, LowChoy N. Standing balance in persistent whiplash: a comparison between subjects with and without dizziness. J Rehabil Med 2005;37:224-229.

Treleaven J, Jull G, LowChoy N. The relationship of cervical joint position error to balance and eye movement disturbances in persistent whiplash. Man Ther 2006;11:99-106.

Treleaven J, Jull G, Sterling M. Dizziness and unsteadiness following whip- lash injury: characteristic features and relationship with cervical joint position error. J Rehabil Med 2003;35:36-43.

Vidal PG. Vertebral artery testing as a clinical screen for vertebrobasilar insufficiency: is there any diagnostic value? Orthopaed Pract 2004;16: 7-12.

Whitney SL, Wrisley DM, Brown KE, Furman JM. Is perception of handicap related to functional performance in persons with vestibular dysfunction? Otol Neurotol 2004;25:139-143.

Wrisley DM, Sparto PJ, Whitney SL, Furman JM. Cervicogenic dizziness: a review of diagnosis and treatment. J Orthop Sports Phys Ther 2000; 30:755-766

Yamauchi M, Yamamoto M, Kitamura K, Morita S, Nagakura R, Matsunaga S, Abe S. Morphological classification and comparison of suboccipital muscle fiber characteristics. Anat Cell Biol 2017;50:247-254.

Young $\mathrm{YH}$, Chen $\mathrm{CH}$. Acute vertigo following cervical manipulation. Laryngoscope 2003;113:659-662.

Zaina C, Grant R, Johnson C, Dansie B, Taylor J, Spyropolous P. The effect of cervical rotation on blood flow in the contralateral vertebral artery. Man Ther 2003;8:103-109. 